\title{
Requirement of Apoptosis-Inducing Kinase 1 for the Induction of Bronchial Asthma following Stimulation with Ovalbumin
}

\author{
Eiko Takada ${ }^{a}$ Masae Furuhata $^{a}$ Susumu Nakae ${ }^{c}$ Hidenori Ichijo $^{d}$ \\ Katsuko Sudo ${ }^{b}$ Junichiro Mizuguchi ${ }^{a}$ \\ ${ }^{\mathrm{a}}$ Department of Immunology, and ${ }^{\mathrm{b}}$ Animal Research Center, Tokyo Medical University, and ${ }^{\mathrm{C}}$ Laboratory of \\ Research Initiative, Institute of Medical Science, and ' Laboratory of Cell Signaling, Graduate School of \\ Pharmaceutical Sciences, University of Tokyo, Tokyo, Japan
}

\section{Key Words}

Asthma $\cdot$ Airway inflammatory disease $\cdot$ Apoptosis

signal-regulating kinase $1 \cdot$ Knock-out mice

\begin{abstract}
Background: Bronchial asthma is a chronic inflammatory disease of the airway. Apoptosis signal-regulating kinase 1 (ASK1), a member of the mitogen-activated protein kinase kinase kinase family, is activated by environmental stress and plays a crucial role in the induction of apoptosis and inflammation. To examine whether ASK1 is involved in the induction of bronchial asthma, we investigated the role of ASK1 using a genetic approach in the production of cytokines, as well as the development of airway hyperreactivity (AHR) and antibody responses using a murine airway inflammation model. Methods: ASK1-deficient (ASK1 ${ }^{-1-}$ ) and control wild-type (WT) mice were immunized with ovalbumin (OVA) without alum intraperitoneally, followed by intranasal administration of OVA. Airway infiltration of inflammatory cells, cytokine production, AHR and antibody production were assayed. The asthmatic phenotype was assessed following intranasal administration of IL-13 or TNF-a. Results: $\mathrm{ASK}^{-/-}$mice sensitized with OVA displayed an impaired inflammatory cell infiltration into airways and a decreased AHR
\end{abstract}

relative to WT mice. Moreover, the production of OVA-specific IgE antibodies and proasthmatic cytokines (IL-5, IL-13 and TNF-a) was substantially reduced in OVA-stimulated $\mathrm{ASK}^{-/-}$mice. Intranasal administration of IL-13 and OVA enhanced the accumulation of inflammatory cells in OVAprimed $\mathrm{ASK}^{-/-}$mice. The OVA-induced AHR in response to methacholine was enhanced by IL-13 in WT mice but not $\mathrm{ASK}^{-/-}$mice. Conclusions: The ASK1 signaling pathway regulates the OVA-induced asthmatic phenotype, specifically AHR sensitivity and cytokine production. Therefore, the ASK1 signaling pathway is a promising target for therapeutic intervention in some asthmatic patients.

๑) 2013 S. Karger AG, Basel

\section{Introduction}

Bronchial asthma is a chronic inflammatory airway disease that is characterized by airway hyperreactivity (AHR), inflammatory cell infiltration and airway remodeling $[1,2]$. This disease is initiated and aggravated by the infiltration of inflammatory cells such as T-helper 2 (Th2) cells, eosinophils, neutrophils and B cells [3]. Upon activation, Th2 cells produce IL-4, IL-5 and IL-13 [4]. IL-4 plays a crucial role in the differentiation and maintenance

\section{KARGER}

E-Mail karger@karger.com

www.karger.com/iaa (c) 2013 S. Karger AG, Basel

$1018-2438 / 13 / 1622-0104 \$ 38.00 / 0$
Correspondence to: Prof. Junichiro Mizuguchi

Department of Immunology, Tokyo Medical University

6-1-1 Shinjuku, Shinjuku-ku

Tokyo 160-8402 (Japan)

E-Mail mizu@ tokyo-med.ac.jp 
of Th2 cells and stimulates B cells to produce IgE and IgG1 [5], while IL-13 is necessary for the effector phase of Th2 responses, including eosinophilia and hyperresponsiveness [6]. Th2 responses are regulated by a variety of factors, including transcription factors GATA3 and NF$\kappa \mathrm{B}$, as well as mitogen-activated protein kinases (MAPKs) [7-9].

In mammalian cells, MAPKs are comprised of extracellular signal-regulated kinases, p38 MAPKs and c-Jun $\mathrm{NH} 2$-terminal kinases (JNKs) [8-11]. MAPKs are activated by a sequential phosphorylation from MAPK kinase kinases (MAP3Ks) to MAPK kinase (MAP2Ks) to MAPKs. Apoptosis signal-regulating kinase 1 (ASK1) is a member of the MAP3K protein family and plays a crucial role in the induction of apoptosis, cell proliferation and inflammation in some cell types [12]. We have recently demonstrated the role of ASK1 activation in the induction of apoptosis by engagement of membrane Ig on B cells [13]. Moreover, lipopolysaccharide binding to Toll-like receptor (TLR)4 activated the ASK1-p38 MAPK signaling pathway and resulted in inflammatory responses [14]. The pattern recognition receptors, TLRs and cytosolic nuclear binding/oligomerization domain leucinerich repeat proteins are utilized by the innate immune systems to detect pathogen-associated molecular patterns, which are highly conserved modules produced by invading pathogens [15].

In the present study, we employed ASK1-deficient $\left(\mathrm{ASK}^{-/-}\right)$mice to determine whether ASK1 activation is involved in the induction of bronchial asthma in response to ovalbumin (OVA) stimulation. ASK1 activation is necessary for the production of proasthmatic cytokines such as IL-5, IL-13 and TNF- $\alpha$ in BAL fluid. Signaling via ASK1 plays a crucial role in the induction of bronchial asthma, likely through cytokine production and AHR. Therefore, the ASK1 signaling pathway would be a suitable therapeutic target for the treatment of antigen-induced bronchial asthma.

\section{Materials and Methods}

Mice

$\mathrm{ASK}^{-1-}$ mice (C57BL/6 background) and control wild-type (WT) mice were bred and maintained at the animal facility of Tokyo Medical University. Experiments were approved by the Ethical Committee of Animal Experiments of Tokyo Medical University.

Histological Analysis of Lung Sections

Lungs were inflated with $4 \%(\mathrm{v} / \mathrm{v})$ formalin/PBS solution $(\mathrm{pH}$ 7.0), embedded in paraffin, and sections were cut for standard HE and PAS staining.
OVA-Induced Airway Inflammation

$\mathrm{ASK}^{-1-}$ and WT mice were sensitized with an intraperitoneal injection of $10 \mu \mathrm{g}$ of OVA (grade V; Sigma-Aldrich, St. Louis, Mo., USA) suspended in PBS (0.2 ml) on days $0,3,5,7,9,11$ and 13. Control mice received the same volume of PBS. Mice were subjected to an intranasal challenge of $200 \mu \mathrm{g}$ OVA or PBS on days 31, 34 and 37. At $24 \mathrm{~h}$ after the last serial OVA administration (day 38), histological sections, AHR, cytokine production, cell proliferation and $\mathrm{Ab}$ production were assayed.

\section{Collection and Differentials of BAL Fluid-Derived Cells}

The airways of the mice were lavaged three times with $1.0 \mathrm{ml}$ of $2 \%$ fetal bovine serum in PBS via a tracheal cannula. BAL fluid was centrifuged and cells were resuspended in $0.5 \mathrm{ml}$ of $2 \%$ fetal bovine serum in PBS. Differential cell counts were carried out using the Sysmex XT-2000iv automated cell counter (Sysmex Corporation, Kobe, Japan).

\section{Measurement of AHR}

Airway responsiveness was assessed using a slightly modified invasive approach using Buxco Research Systems (Wilmington, N.C., USA) as previously reported by Hamelmann et al. [16]. Briefly, in vivo lung resistance $\left(\mathrm{R}_{\mathrm{L}}\right)$ was measured in mice that were anesthetized with xylazine $(10 \mathrm{mg} / \mathrm{kg}$ body weight $) /$ ketamine $(100$ $\mathrm{mg} / \mathrm{kg}$ body weight), tracheotomized and connected to a ventilator. Mice were ventilated with a tidal volume of $0.25 \mathrm{ml}$ and $2 \mathrm{~cm}$ $\mathrm{H}_{2} \mathrm{O}$ positive end-expiratory pressure. Data before methacholine challenge were collected for $3 \mathrm{~min}$ to establish the baseline for each animal. Data regarding $\mathrm{R}_{\mathrm{L}}$ were collected for $3 \mathrm{~min}$ after aerosolized methacholine challenge $(0,3.125,6.25,12.5,25$ and $50 \mathrm{mg} /$ $\mathrm{ml}$ ). The mean response for each dose of methacholine was determined and $\mathrm{R}_{\mathrm{L}}$ was calculated by the percent change from baseline after PBS aerosol treatment.

Ab Quantification by Enzyme-Linked Immunosorbent Assay

Serum Ig levels were determined by enzyme-linked immunosorbent assay (ELISA) according to a modified procedure as previously described [17].

\section{Measurement of Cytokine Levels}

The levels of IFN- $\gamma$, TNF- $\alpha$, IL-4, IL-5, IL- 6 , IL-10 and IL-12 in BAL fluid were determined using the Meso Scale Discovery Platform (Gaithersburg, Md., USA), according to the manufacturer's recommendations. ELISA Ready Set (eBioscience, San Diego, Calif., USA) was used for measurement of IL-13, IL-17 and TNF- $a$. To measure the cytokine production by spleen cells, $4 \times 10^{6} / \mathrm{ml}$ cells were plated in 24-well plates ( $1 \mathrm{ml} /$ well) and cultured with or without $40 \mu \mathrm{g} / \mathrm{ml}$ of OVA for $72 \mathrm{~h}$, and supernatants were assayed by ELISA for IL-13 and TNF- $\alpha$ production.

\section{${ }^{3} \mathrm{H}$-Thymidine Incorporation in vitro}

Single cell suspensions were prepared from the spleens of mice that were primed with or without OVA by teasing. Cells $\left(4 \times 10^{6} /\right.$ $\mathrm{ml}$ ) were cultured in 96-well plates with $40 \mu \mathrm{g} / \mathrm{ml}$ of OVA for $72 \mathrm{~h}$ and pulsed with $1 \mu \mathrm{Ci}(1 \mathrm{mCi}=37 \mathrm{MBq}){ }^{3} \mathrm{H}$-thymidine/well for the final $8 \mathrm{~h}$. The incorporated ${ }^{3} \mathrm{H}$-thymidine was counted in a liquid scintillation counter. 
Fig. 1. The OVA-induced bronchial asthma phenotype is compromised in $\mathrm{ASK} 1^{-/-}$ mice. Mice were sensitized by an intraperitoneal injection of $10 \mu \mathrm{g}$ of OVA in PBS 7 times, followed by intranasal administration of OVA or PBS. The day after the final OVA instillation, inflammatory cell infiltration in the airways was assessed. a Representative lung sections from $\mathrm{ASK} 1^{-/}$and control WT mice were stained with $\mathrm{HE}$ $(\times 100$ and $\times 200$, as indicated). b Total cells in BAL fluid from $\mathrm{ASK}^{-/-}$and control WT mice are shown. Data are representative of 3 independent experiments of 10 mice/group. Error bars represent the SD. $* \mathrm{p}<0.05$.

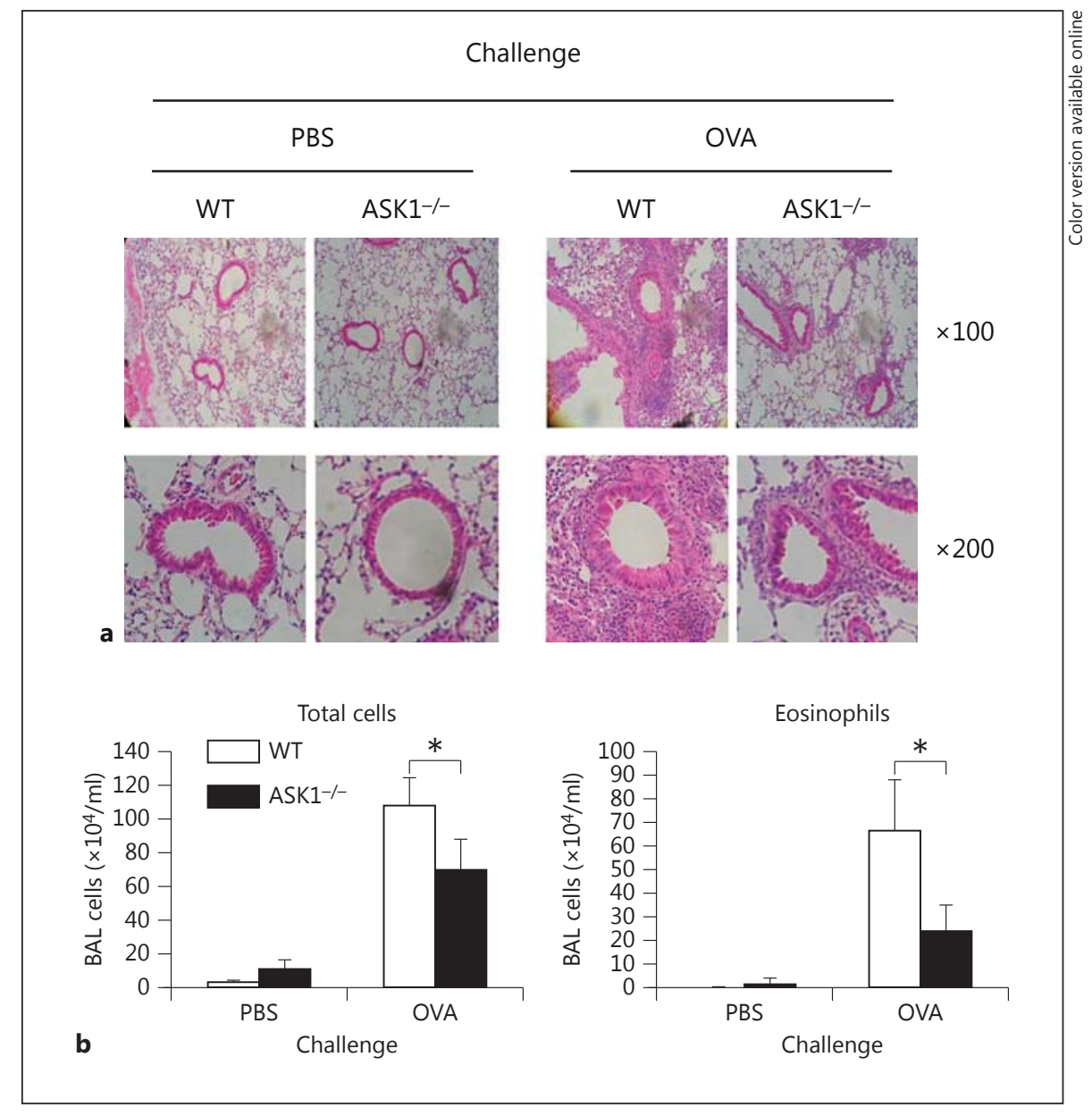

Flow Cytometric Analysis of Cytokine Production

Cells from BAL fluid were stained with APC-anti-CD11c and FITC-anti-Gr1, followed by fixation and permeabilization using Fixation and Permeabilization Solution (BD Bioscience, San Jose, Calif., USA). Then, cells were stained with PE-anti-TNF-a (BioLegend, San Diego, Calif., USA) or PE-anti-IL-13 (eBioscience), and subjected to flow cytometric analysis (FACSCalibur, Nippon Becton Dickinson Company Ltd., Tokyo, Japan).

Intranasal Administration of IL-13 or TNF- $\alpha$

Mice primed with or without OVA were anesthetized with 2\% isoflurane and then challenged with intranasal administration of TNF- $\alpha$ (50 ng/20 $\mu$ PBS with $0.1 \%$ BSA/mouse, once) or IL-13 $(1 \mu \mathrm{g} / 20 \mu \mathrm{l}$ PBS with $0.1 \% \mathrm{BSA} / \mathrm{mouse}$, daily for 3 consecutive days). BAL and AHR were determined $24 \mathrm{~h}$ after the administration of TNF- $\alpha$ or IL-13.

\section{Statistical Analysis}

Data are expressed as means \pm SD for each group. Statistical significance was determined by Student's t test.

\section{Results}

Attenuation of OVA-Induced Bronchial Pulmonary

Pathologies and Decreased Inflammatory Cell

Infiltration in $\mathrm{ASK}^{-/-}$Mice

$\mathrm{ASK}^{-1-}$ and WT mice were sensitized with OVA or left untreated and subsequently challenged with OVA aerosol or PBS alone. At $24 \mathrm{~h}$ after the final challenge, the mice were assayed for lung pathology and BAL cellularity. Control WT mice developed inflammatory lesions in the peribronchial and perivascular regions in response to OVA; however, the extent of the inflammatory lesion was reduced in $\mathrm{ASK}^{-/-}$mice (fig. 1a). Goblet cell hyperplasia, as assessed by PAS staining, was also attenuated in OVAstimulated $\mathrm{ASK}^{-/-}$mice relative to the control [Takada et al., unpubl. observation]. OVA-induced bronchial asthma was accompanied by an accumulation of cells in the airway. The number of total cells and eosinophils accumulated in the airways of ASK1-/- mice was reduced rela- 


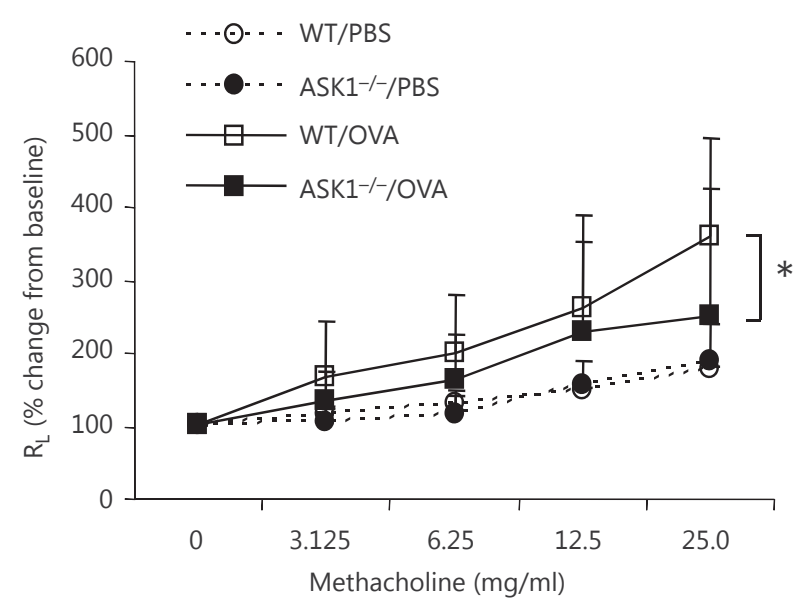

Fig. 2. OVA-induced enhancement of AHR in response to methacholine is compromised in $\mathrm{ASK}^{-/-}$mice. Mice sensitized with OVA were assayed for AHR in response to various concentrations of methacholine. Data are representative of 3 independent experiments of 5-10 mice/group. Error bars represent the SD. ${ }^{*} \mathrm{p}<0.05$.

tive to WT mice (fig. 1b). These results indicate that OVA-induced pulmonary inflammatory responses are attenuated in $\mathrm{ASK}^{-/-}$mice.

\section{OVA-Induced Enhancement of AHR in Response to}

Methacholine Is Decreased in ASK1 $1^{-/}$Mice

The dose-dependent change in $\mathrm{R}_{\mathrm{L}}$ following methacholine challenge was substantially higher in WT mice treated with OVA aerosol than mice treated with PBS alone (fig. 2). In contrast, the administration of OVA aerosol to $\mathrm{ASK}^{-1-}$ mice decreased the dose-dependent change in $\mathrm{R}_{\mathrm{L}}$ following methacholine challenge compared with controls. Therefore, in addition to the regulation of inflammatory cell infiltration, ASK1 also regulates the development of AHR.

\section{OVA-Induced IgE Production Is Attenuated in}

\section{ASK1 $1^{-/-}$Mice}

Since bronchial asthma is closely associated with IgE antibody production [4], Ab levels in sera from OVAstimulated $\mathrm{ASK}^{-/-}$and control WT mice were determined by ELISA. Anti-OVA-specific IgE Ab production in $\mathrm{ASK} 1^{-/-}$mice was considerably reduced compared with control WT mice. This appeared to be specific to IgE since other isotypes of anti-OVA-specific Abs such as IgM, IgG1 and IgG2a [also IgG2b and IgG3; Takada et al., unpubl. observation] were not statistically different between $\mathrm{ASK}^{-1-}$ and WT mice (fig. 3). These results suggest that ASK1 regulates IgE Ab production in the mouse model of OVA-induced airway inflammatory disease.

OVA-Induced Th2 Cytokine Production Is Attenuated in BAL Fluid from ASK1 ${ }^{-/-}$Mice

Since IgE Ab production is regulated by Th 2 cytokines [5], we assayed cytokine levels in the BAL fluid from OVA-stimulated mice by ELISA. ASK $1^{-/-}$mice produced diminished levels of IL-5 and IL-13 relative to WT mice, although comparable levels of IL-4 were produced (fig. 4a). TNF- $\alpha$ levels were also substantially reduced in $\mathrm{ASK}^{-1-}$ mice. Levels of other cytokines including IFN $-\gamma$, IL-6, IL-10, IL-12 and IL-17A were largely comparable between $\mathrm{ASK}^{-/-}$and WT mice (fig. 4a) [unpubl. observation].

To assess the population of cytokine-producing cells in BAL fluids, IL-13- or TNF- $\alpha$-producing cells were determined by flow cytometry (fig. $4 \mathrm{~b}$ ). Similar to previous reports by de Heer et al. [18], we detected several percentages of macrophages $\left(\mathrm{Gr}-1^{+}, \mathrm{CD} 11 \mathrm{c}^{+}\right)$and lymphocytes $\left(\mathrm{Gr}-1^{-}, \mathrm{CD} 11 \mathrm{c}^{-}\right)$producing TNF- $\alpha$ or IL-13, or both, in control mice. The frequency of these cells was substantially reduced in $\mathrm{ASK}^{-/-}$, such that we detected percentage macrophages and percentage lymphocytes producing TNF- $\alpha$ or IL-13, or both. We confirmed these cells as macrophages and lymphocytes by Giemsa staining [Takada et al., unpubl. observation]. These findings suggest that ASK1 regulates the recruitment of cytokine-secreting cells into bronchial airways.

\section{IL-13 Production by OVA-Stimulated ASK1 ${ }^{--}$Spleen Cells ex vivo Is Substantially Reduced}

To examine whether cytokine production in secondary lymphoid organs is also regulated by ASK1, spleen cells from the OVA-stimulated mice were cultured with or without OVA for $72 \mathrm{~h}$ in vitro, and then assayed for the production of IL-13 and TNF- $\alpha$. Although OVA induced the production of IL-13 by ASK1-/- cells, the level was decreased relative to WT cells. The production of TNF- $\alpha$ by ASK1 ${ }^{-1-}$ cells and WT cells was similar (fig. 5a). OVAinduced proliferation of spleen cells was comparable between $\mathrm{ASK}^{-/-}$and the control group (fig. 5b). Thus, ASK1 does not regulate the proliferation of splenocytes or the production of TNF- $\alpha$ in response to antigenic stimulation, but rather specifically regulates IL-13 production. 
Fig. 3. Anti-OVA IgE antibody production is decreased in $\mathrm{ASK}^{-/-}$mice. The sera of mice sensitized with OVA were assayed for anti-OVA IgM, IgG1, IgG2a, IgG2b, IgG3, and IgE Abs by ELISA. Data are representative of 3 independent experiments of 5-10 mice/group. Error bars represent the SD. ${ }^{*} \mathrm{p}<0.05$.

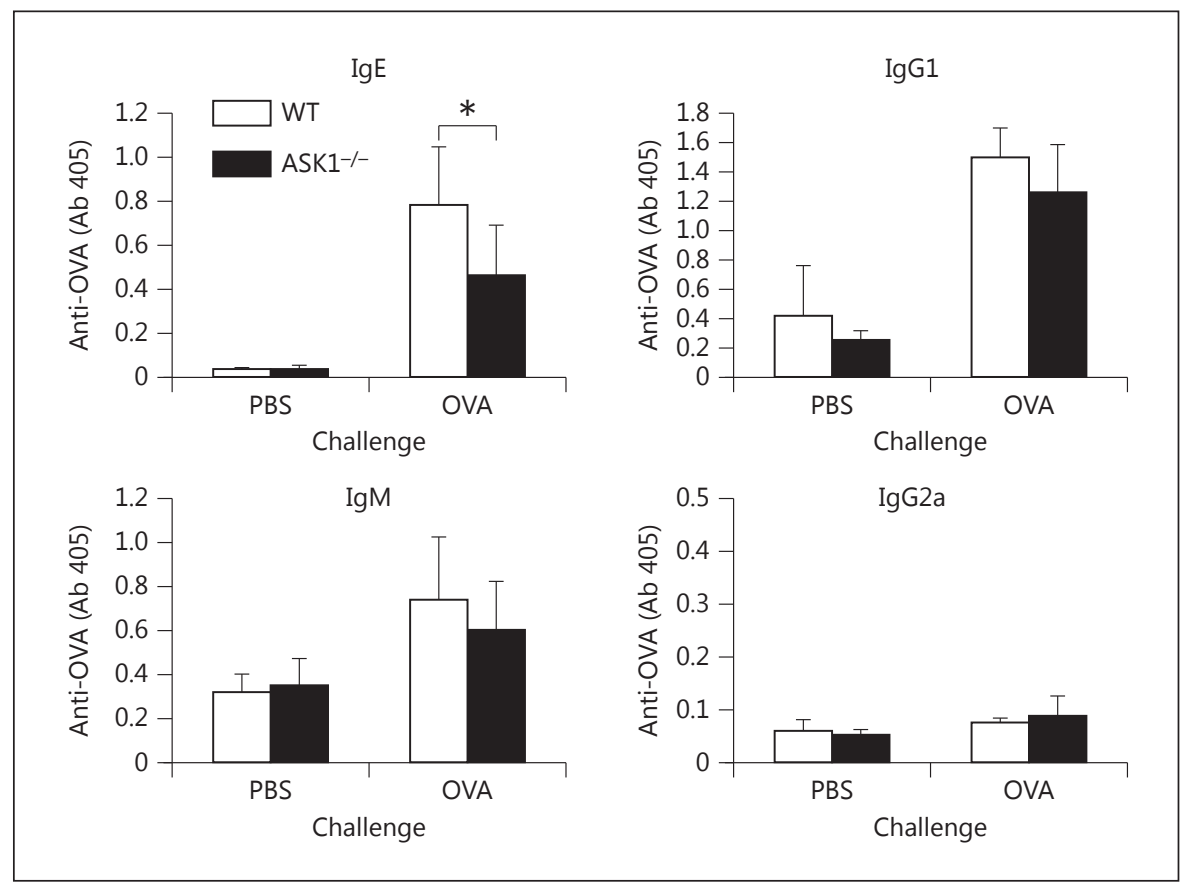

Intranasal Administration of IL-13 Restores

Inflammatory Cell Accumulation in the Airways of

OVA-Stimulated ASK1 ${ }^{-/-}$Mice

To examine whether the diminished cytokine levels are responsible for the OVA-induced asthmatic phenotype in $\mathrm{ASK}^{-1-}$ mice, IL- 13 was administered intranasally into the OVA-primed $\mathrm{ASK}^{-/-}$and WT mice together, with or without stimulation with OVA, and BAL cells were enumerated. As shown in figure 6, the accumulation of inflammatory cells, including eosinophils, neutrophils, macrophages and lymphocytes, was diminished in $\mathrm{ASK}^{-/-}$mice relative to WT mice. The intranasal coadministration of IL-13 and OVA to OVA-primed ASK1 $1^{-/-}$mice restored inflammatory cell accumulation in $\mathrm{ASK}^{-/-}$airways to levels comparable to that of WT mice. IL-13 alone had a minor effect on eosinophil accumulation in both $\mathrm{ASK} 1^{-/-}$and WT mice (fig. 6). Likewise, the intranasal administration of TNF- $\alpha$ plus OVA into the OVA-primed ASK1 ${ }^{-/-}$mice partially restored the accumulation of eosinophils, with limited impact on the accumulation of neutrophils and lymphocytes. Interestingly, TNF- $\alpha$ increased OVA-induced macrophage recruitment in control WT mice and $\mathrm{ASK}^{-/-}$mice, suggesting that ASK1 regulates recruitment of macrophages into the airways via the production of TNF- $\alpha$. These results suggest that ASK1 regulates cytokine production and the recruitment of inflammatory cells into the airways, which contribute to the asthmatic phenotype.
Intranasal Administration of IL-13 Induces AHR in WT, but Not ASK1 ${ }^{-/-}$Mice

Intranasal administration of IL-13 has previously been shown to increase AHR [19]. We sought to determine whether intranasal administration of IL-13 to $\mathrm{ASK}^{-/-}$ mice could induce AHR in response to methacholine. As expected, the administration of IL-13 to unprimed WT mice resulted in a significant increase in AHR, which was not observed in $\mathrm{ASK}^{-/-}$mice (fig. 7). Administration of TNF- $\alpha$ alone showed a similar tendency to cause an increase in AHR, although this was not statistically significant [unpubl. observation]. These results suggest that $\mathrm{ASK}^{-/-}$mice are largely resistant to cytokine-induced increases in AHR. Together, ASK1 regulates airway hypersensitivity in response to cytokines as well as antigenic stimulation (OVA).

\section{Discussion}

Recent studies demonstrate the efficacy of p38MAPKs (SB239063) and JNK (SP600125) inhibitors using the animal models of bronchial asthma [20, 21]. Moreover, JunB has been reported to participate in the development of Th2 immune responses [22]. However, interpretation of these data needs careful consideration because of possible nonspecific effects of inhibitors used. Thus, we took 
Fig. 4. Cytokine profile of the BAL fluid and cells from $\mathrm{ASK}^{-/}$and control WT mice sensitized with OVA. a BAL fluids from OVA-sensitized ASK1 $1^{-/-}$and control WT mice were assayed for cytokines by ELISA. Data are representative of 3 independent experiments of 5 mice/group. Error bars represent the SD. ${ }^{*} \mathrm{p}<0.05$.
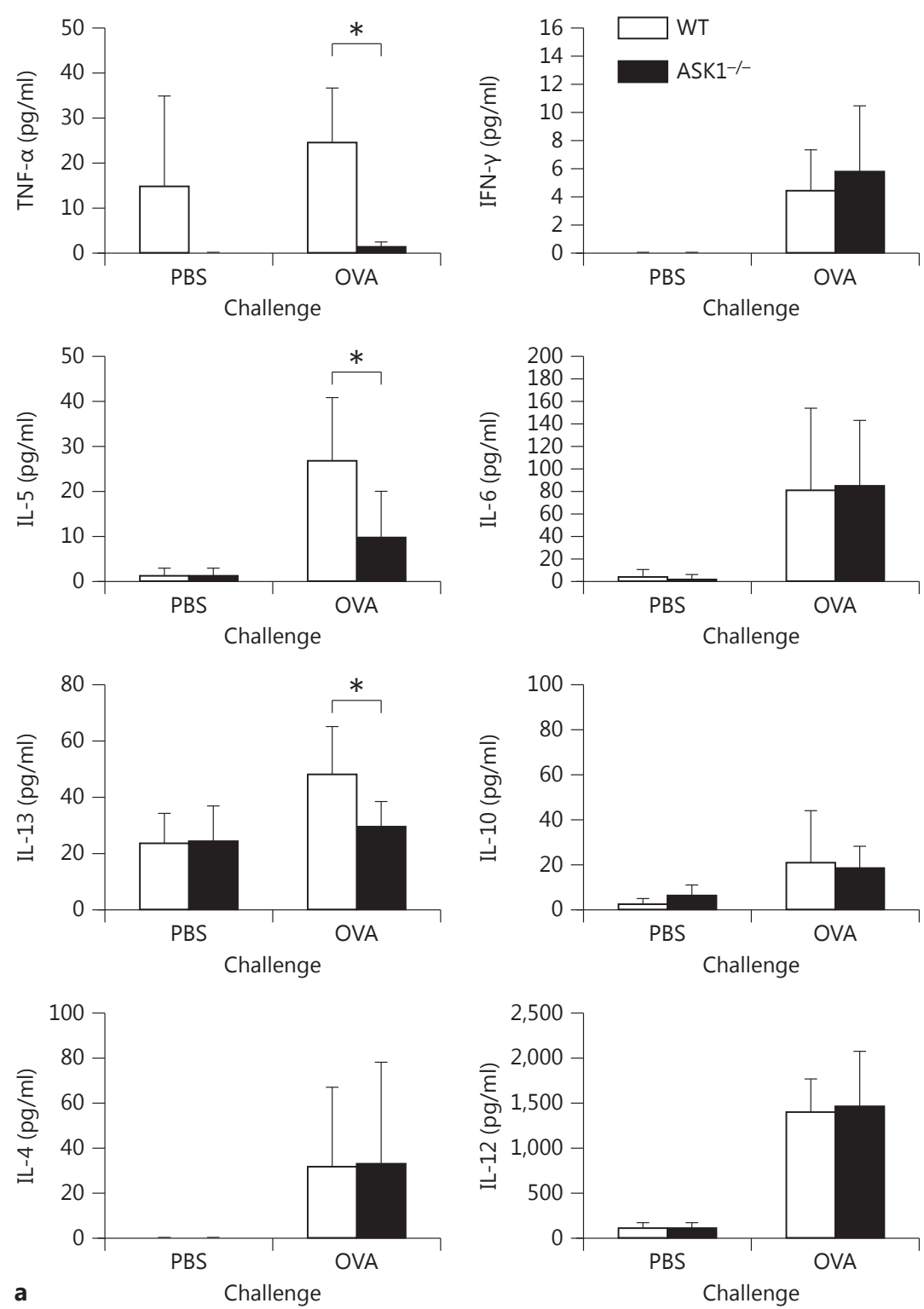

a genetic approach in vivo to investigate the role of MAPKs cascade using mice deficient in ASK1, an upstream component of JNKs and p38MAPKS, on an antigen-induced asthma. The OVA-induced accumulation of inflammatory cells into the airways, including eosinophils, lymphocytes, macrophages and neutrophils, was attenuated in $\mathrm{ASK}^{-/-}$mice relative to WT mice. In addition, OVA-induced increase of AHR in response to methacholine was also reduced in $\mathrm{ASK}^{-/-}$mice, suggesting that antigen-induced airway inflammation is accom- panied by an increase in AHR to methacholine, as previously proposed [23]. Thus, ASK1 appears to regulate the bronchial asthmatic phenotype in C57BL/6 mice in response to OVA without alum via modulation of downstream signaling pathways. Bronchial asthmatic phenotypes including antigen-induced increase in Th2 cytokine production in response to an environmental antigen are regulated by several transcription factors, such as GATA3, Stats, NF- $\kappa$ B and AP- $1[7,24,25]$. AP-1, consisting of cJun and Fos, is activated by 38 MAPK and the JNK sig- 


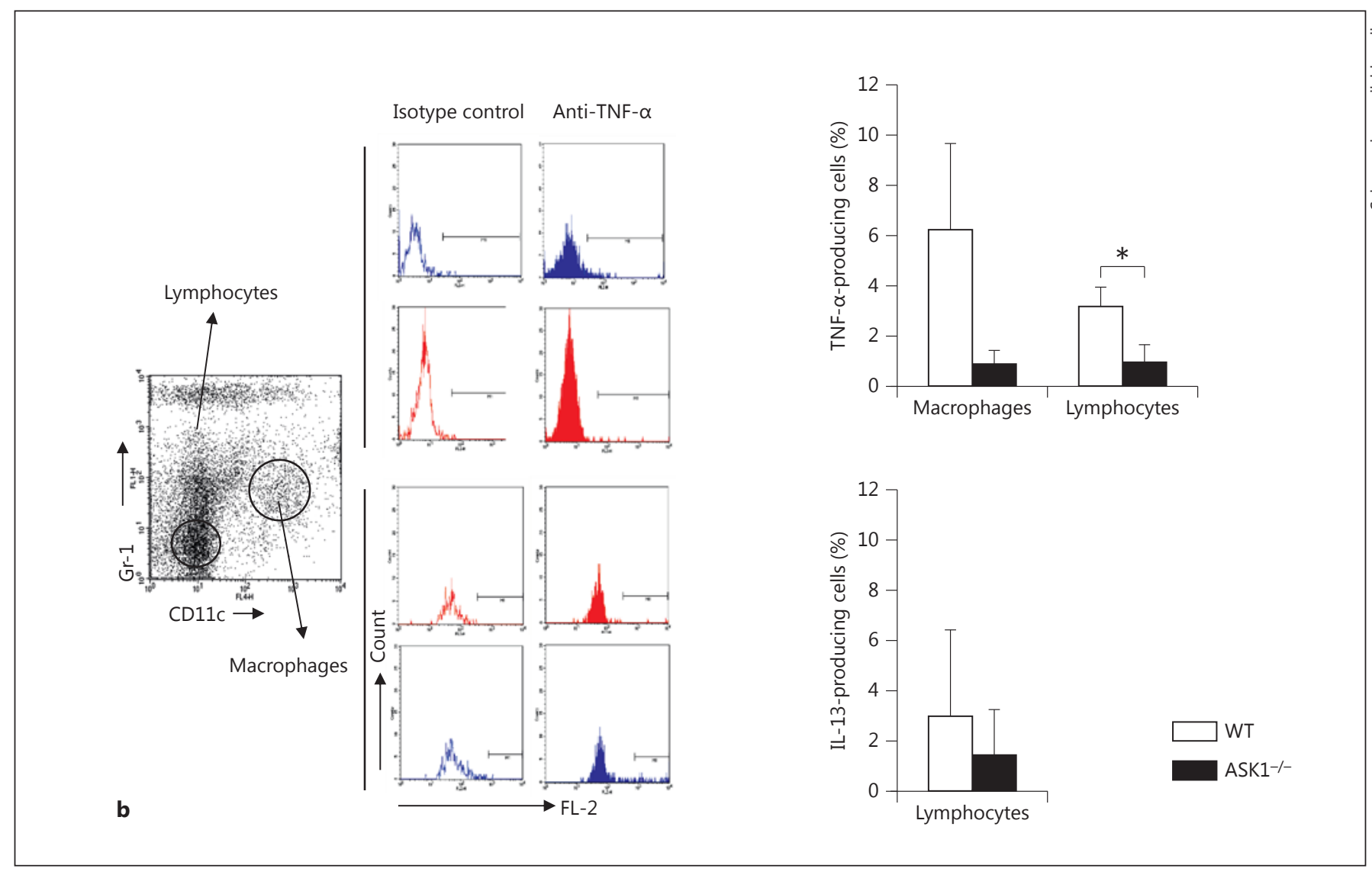

Fig. 4. Cytokine profile of the BAL fluid and cells from ASK1 ${ }^{-1-}$ and control WT mice sensitized with OVA. b The proportion of IL-13-producing lymphocytes and TNF-a-producing macrophages or lymphocytes in BAL fluids from the OVA-sensitized ASK $1^{-1-}$ and control WT mice. Data are representative of 3 independent experiments of 5 mice/group. Error bars represent the SD. ${ }^{*} \mathrm{p}<0.05$.
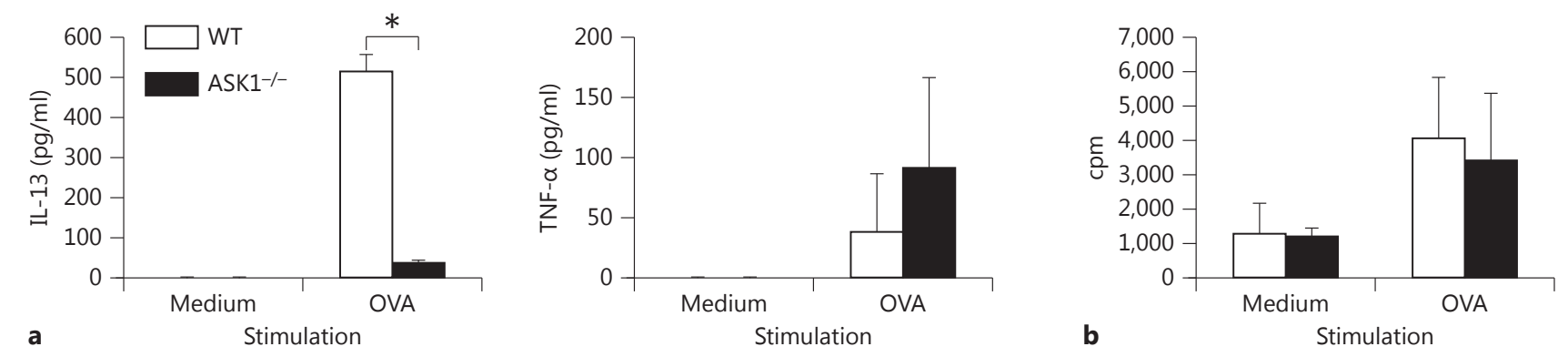

Fig. 5. IL-13 production by ASK1 ${ }^{-1-}$ spleen cells is diminished relative to controls. Spleen cells from OVA-sensitized ASK1 ${ }^{-1-}$ mice and control WT mice were cultured with $40 \mu \mathrm{g} / \mathrm{ml}$ of OVA or medium alone. IL-13 and TNF- $\alpha$ (a) and ${ }^{3} \mathrm{H}$-thymidine incorporation (b) were assayed after $72 \mathrm{~h}$. Data are representative of 3 independent experiments of 3 mice/group. Error bars represent the SD. ${ }^{*} \mathrm{p}<0.05$. 


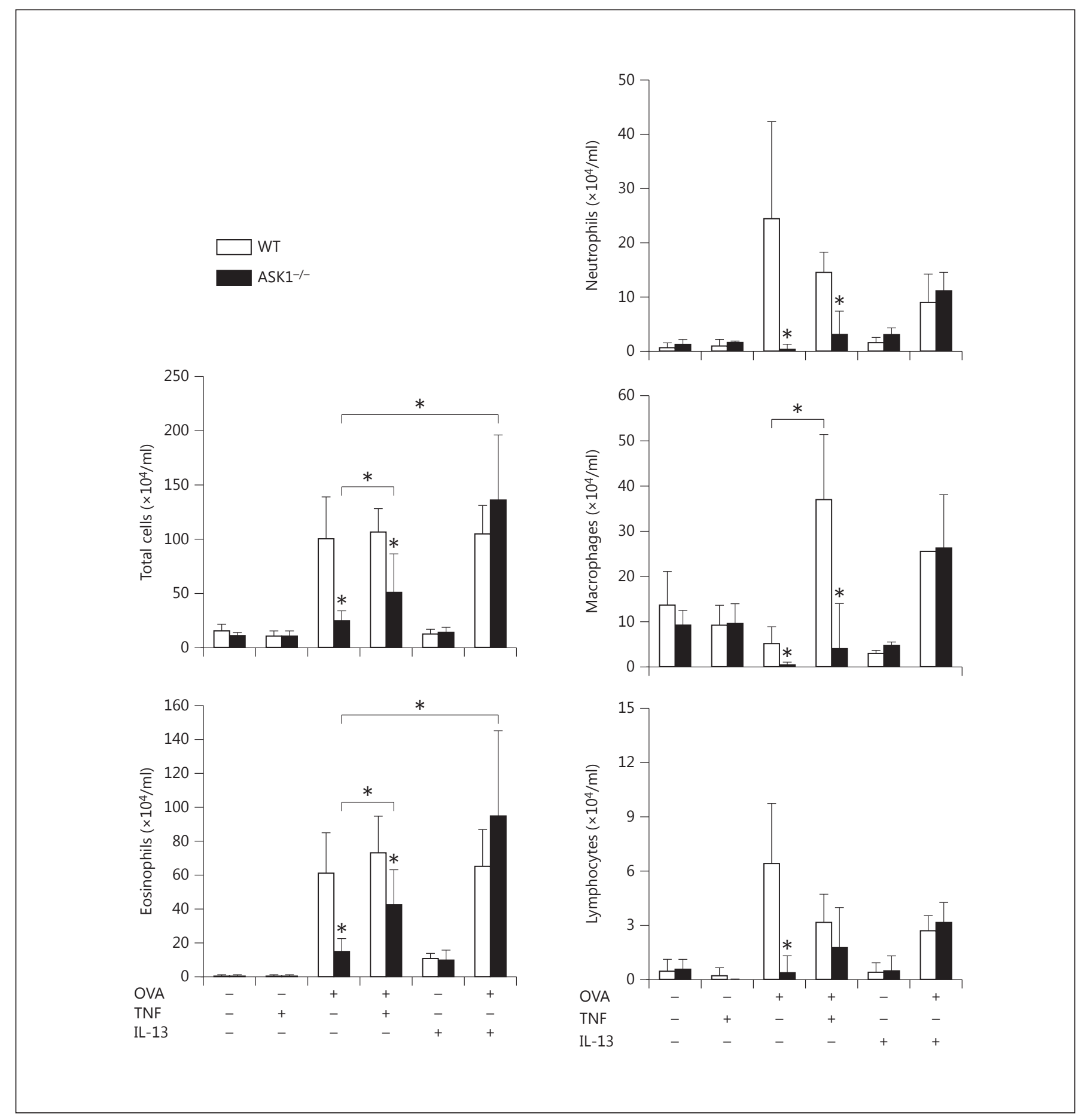

Fig. 6. Intranasal administration of IL-13 or TNF- $\alpha$ restores OVA-induced inflammatory cell infiltration into the airways. The mice primed with OVA received intranasal administration of OVA or PBS in the presence or absence of IL-13 ( $1 \mu \mathrm{g} / \mathrm{mouse})$ or TNF- $\alpha$ ( $50 \mathrm{ng} / \mathrm{mouse})$. One day after the final challenge, the accumulation of cells in the BAL fluid was assayed. Data are representative of 3 independent experiments of 5-7 mice/group. Error bars represent the SD. ${ }^{*} \mathrm{p}<0.05$. 


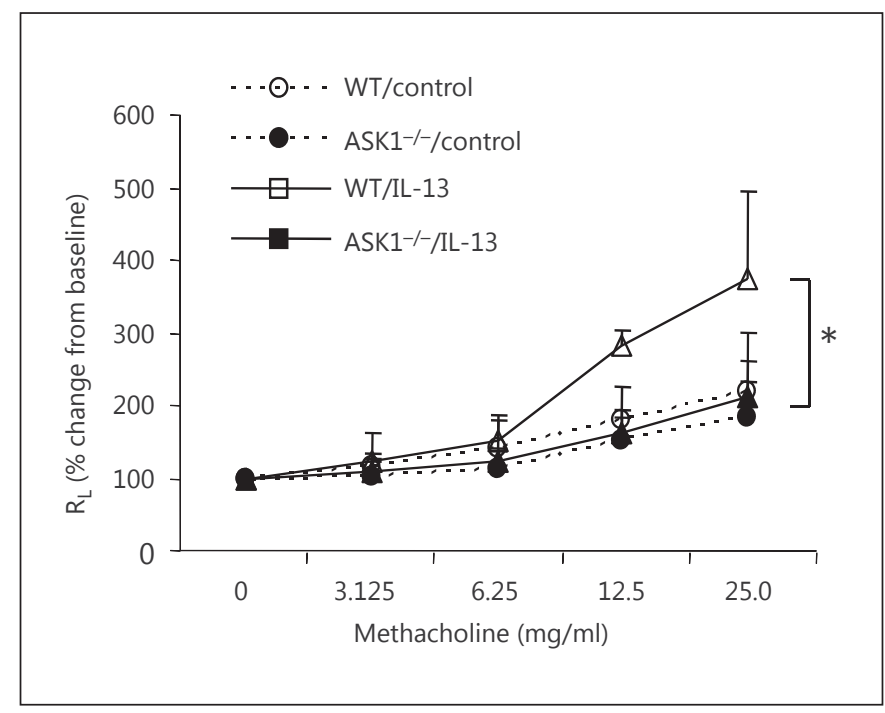

Fig. 7. Intranasal administration of IL-13 into $\mathrm{ASK} 1^{-/-}$mice did not enhance the AHR response to methacholine. The AHR responses to methacholine for unprimed $\mathrm{ASK}^{-/-}$and WT mice that received IL-13 alone intranasally 3 times are also shown. Data are representative of 3 independent experiments of 5-7 mice/group. Error bars represent the SD. ${ }^{*} \mathrm{p}<0.05$.

naling pathway, which in turn are regulated by upstream kinases, including the MAP2Ks and MAP3Ks, such as ASK1 $[8,11,12]$. In BAL fluid from ASK1 ${ }^{-/-}$mice the levels of IL-5 and IL-13, but not IL-4, were moderately decreased compared with control WT mice. The reduced production of IL-5 in ASK $1^{-/-}$mice likely contributed to the impaired accumulation of eosinophils in their BAL fluid because IL- 5 and eotaxin regulate the recruitment of eosinophils into airways $[26,27]$. Divergent production of IL-4 and IL-13 was found among innate immune cells: innate Th2 cells produce IL-13 and basophils produce IL-4 [28], although the production of IL-4, IL-5 and IL-13 by Th2 cells is regulated by GATA 3 and Stat 6 together with IL-2-mediated Stat5. Indeed, OVA-induced IL-13 production by spleen cells and the frequency of IL13 -producing cells in the airways were also decreased in $\mathrm{ASK}^{-/-}$mice. Which types of cells produce IL-4 remains unclear in the present study.

IL-13 is a critical mediator of asthma pathology, including accumulation of inflammatory cells into the airway and $\operatorname{IgE}$ antibody responses $[4,6,7]$. Intranasal administration of IL-13 into OVA-stimulated ASK1 ${ }^{-/-}$mice enhanced the accumulation of inflammatory cells (including eosinophils) in BAL fluid to levels similar to WT mice. Eosinophils reportedly play a crucial role in Th2 immune responses [29] through the recruitment of Th2 cells, which creates a positive feedback loop. Thus, ASK1 regulates the production of Th2 cytokines (IL-13 and IL5) in response to OVA, and the accumulation of inflammatory cells in the airway and IgE antibody production.

In addition to typical Th2 cytokines IL-4, IL-5 and IL13 , TNF- $\alpha$ is reported to play a crucial role in the induction of bronchial asthma in some contexts $[1,25,30]$. The levels of the proinflammatory cytokine TNF- $\alpha$ were substantially suppressed in $\mathrm{ASK} 1^{-1-} \mathrm{BAL}$ fluid, but not in sera [unpubl. observation]. Moreover, the proportion of TNFa-producing cells in $\mathrm{ASK}^{-1-} \mathrm{BAL}$ fluid was decreased, although OVA-sensitized $\mathrm{ASK}^{-/-}$spleen cells have the capacity to produce TNF- $\alpha$ to levels equal to WT mice in response to OVA stimulation in vitro, suggesting that ASK1 regulates the recruitment of TNF- $\alpha$-producing cells into the airway lesion. However, TNF- $\alpha$ production by $\mathrm{ASK}^{-/-}$spleen cells in response to lipopolysaccharide stimulation was reportedly considerably decreased [14]. These data suggest that the requirement for ASK1 differs based on the stimulant, for example a TLR ligand versus an allergen.

TNF- $\alpha$ treatment of OVA-primed ASK1 ${ }^{-/-}$mice partially restored the accumulation of eosinophils. This is in line with previous studies that reported a role for TNF- $\alpha$ in the development of the asthmatic phenotype in response to some antigens without alum $[25,31,32]$. However, it is important to note that different results have been reported in other experimental settings, suggesting that the role of TNF- $\alpha$ for the induction of the asthmatic phenotype was dependent on the genetic background of the mouse model and adjuvant used for immunization $[30,33]$.

Cytokine-mediated inflammatory reaction as well as structural changes in the airways regulates development of AHR [34, 35]. For example, IL-13 has been reported to increase in AHR to methacholine [19]. However, naïve $\mathrm{ASK}^{-/-}$mice did not respond to IL-13 to display an increase in AHR, although such an increase in AHR was found in control WT mice, suggesting that ASK1 regulates AHR sensitivity to methacholine in a murine OVA-induced asthma model. Indeed, IL-13 directly activated bronchial smooth muscle cells $[19,36]$, leading to an increase in AHR. It is possible that IL-13-mediated activation of smooth muscle cells involves the ASK1 activation pathway. Together, ASK1 appears to regulate the asthmatic phenotype, probably through multiple events including cytokine production in peripheral lymphoid organs, recruitment of cytokine-producing cells in the airway, and sensitivity to cytokine to undergo an increase in AHR. 
Our present results clearly demonstrate that ASK1 is involved in the induction of OVA-induced bronchial asthma in vivo. Although most asthmatic patients respond well to the current treatment of inhaled corticosteroid and $\beta$-adrenergic agents, some patients with severe disease are refractory to such treatments [37]. Thus, new treatment modalities are required for the refractory asthma phenotypes. Steroid-resistant asthmatics demonstrated elevated levels of JNK and AP1 $[38,39]$, which is proposed to neutralize activated glucocorticoid receptor, resulting in refractoriness to glucocorticoid-induced suppressive effects, suggesting that therapeutic targeting of the JNK-AP-1 pathway [40] is an effective treatment modality for corticosteroid-resistant asthma. Indeed, both
$\mathrm{JNK}^{-1-}$ and $\mathrm{JNK} 2^{-/-}$mice showed a diminished bronchial asthmatic phenotype in response to OVA [Takada et al., unpubl. observation]. Together, our present studies demonstrated that ASK1-mediated signaling pathway(s) are a novel target for therapeutic intervention in some asthmatic patients.

\section{Acknowledgements}

This work was supported by a grant from the Intractable Immune System Disease Center of Tokyo Medical University, which is supported by the Ministry of Education, Culture, Sports, Science and Technology of Japan.

\section{References}

1 Barnes PJ: Immunology of asthma and chronic obstructive pulmonary disease. Nat Rev Immunol 2008;8:183-192.

2 Hammad H, Lambrecht BN: Dendritic cells and epithelial cells: linking innate and adaptive immunity in asthma. Nat Rev Immunol 2008;8:193-204.

-3 Lloyd CM, Hessel EM: Functions of T cells in asthma: more than just $\mathrm{T}_{\mathrm{H}} 2$ cells. Nat Rev Immunol 2010;10:838-848.

-4 Finkelman FD, Hogan SP, Hershey GK, Rothenberg ME, Wills-Karp M: Importance of cytokines in murine allergic airway disease and human asthma. J Immunol 2010;184: 1663-1674.

5 Snapper CM, Finkelman FD, Paul WE: Regulation of IgG1 and IgE production by interleukin 4. Immunol Rev 1988;102:51-75.

-6 Kasaian MT, Miller DK: IL-13 as a therapeutic target for respiratory disease. Biochem Pharmacol 2008;76:147-155.

7 Paul WE, Zhu J: How are $\mathrm{T}_{\mathrm{H}}$ 2-type immune responses initiated and amplified? Nat Rev Immunol 2010;10:225-235.

8 Rincon M, Davis RJ: Regulation of the immune response by stress-activated protein kinases. Immunol Rev 2009;228:212-224.

9 Zhang YL, Dong C: Map kinases in immune responses. Cell Mol Immunol 2005;2:20-27.

10 Chang L, Karin M: Mammalian map kinase signalling cascades. Nature 2001;410:37-40.

- 11 Raman M, Chen W, Cobb MH: Differential regulation and properties of MAPKs. Oncogene 2007;26:3100-3112

12 Hayakawa T, Matsuzawa A, Noguchi T, Takeda K, Ichijo H: The ASK1-MAP kinase pathways in immune and stress responses. Microbes Infect 2006;8:1098-1107.
13 Furuhata M, Takada E, Noguchi T, Ichijo H, Mizuguchi J: Apoptosis signal-regulating kinase (ASK)-1 mediates apoptosis through activation of JNK1 following engagement of membrane immunoglobulin. Exp Cell Res 2009;315:3467-3476.

14 Matsuzawa A, Saegusa K, Noguchi T, Sadamitsu C, Nishitoh H, Nagai S, Koyasu S, Matsumoto K, Takeda K, Ichijo H: ROS-dependent activation of the TRAF6-ASK1-p38 pathway is selectively required for TLR4-mediated innate immunity. Nat Immunol 2005; 6:587-592.

15 Kawai T, Akira S: The role of pattern-recognition receptors in innate immunity: update on Toll-like receptors. Nat Immunol 2010;11: 373-384.

16 Hamelmann E, Schwarze J, Takeda K, Oshiba A, Larsen GL, Irvin CG, Gelfand EW: Noninvasive measurement of airway responsiveness in allergic mice using barometric plethysmography. Am J Respir Crit Care Med 1997;156: 766-775.

17 Cao Y, Takada E, Hata K, Sudo K, Furuhata M, Mizuguchi J: Enhanced T cell-independent antibody responses in c-Jun $\mathrm{N}$-terminal kinase 2 (JNK2)-deficient B cells following stimulation with Cpg-1826 and anti-IgM. Immunol Lett 2010;132:38-44.

18 de Heer HJ, Hammad H, Soullie T, Hijdra D, Vos N, Willart MA, Hoogsteden HC, Lambrecht $\mathrm{BN}$ : Essential role of lung plasmacytoid dendritic cells in preventing asthmatic reactions to harmless inhaled antigen. J Exp Med 2004;200:89-98.

19 Eum SY, Maghni K, Tolloczko B, Eidelman DH, Martin JG: IL-13 may mediate allergeninduced hyperresponsiveness independently of IL-5 or eotaxin by effects on airway smooth muscle. Am J Physiol Lung Cell Mol Physiol 2005;288:L576-L584.
20 Duan W, Wong WS: Targeting mitogen-activated protein kinases for asthma. Curr Drug Targets 2006;7:691-698.

21 Eynott PR, Xu L, Bennett BL, Noble A, Leung SY, Nath P, Groneberg DA, Adcock IM, Chung KF: Effect of an inhibitor of Jun Nterminal protein kinase, SP600125, in single allergen challenge in sensitized rats. Immunology 2004;112:446-453.

22 Hartenstein B, Teurich S, Hess J, Schenkel J, Schorpp-Kistner M, Angel P: Th2 cell-specific cytokine expression and allergen-induced airway inflammation depend on JunB. EMBO J 2002;21:6321-6329.

23 Cockcroft DW, Davis BE: Mechanisms of airway hyperresponsiveness. J Allergy Clin Immunol 2006;118:551-559, quiz 560-551.

24 Pouliot P, Olivier M: Opposing forces in asthma: regulation of signaling pathways by kinases and phosphatases. Crit Rev Immunol 2009;29:419-442.

25 Nakae S, Lunderius C, Ho LH, Schafer B, Tsai $\mathrm{M}$, Galli SJ: TNF can contribute to multiple features of ovalbumin-induced allergic inflammation of the airways in mice. J Allergy Clin Immunol 2007;119:680-686.

26 Luster AD: Chemokines - chemotactic cytokines that mediate inflammation. $\mathrm{N}$ Engl J Med 1998;338:436-445.

27 Wang JM, Rambaldi A, Biondi A, Chen ZG, Sanderson CJ, Mantovani A: Recombinant human interleukin 5 is a selective eosinophil chemoattractant. Eur J Immunol 1989;19: 701-705.

28 Liang HE, Reinhardt RL, Bando JK, Sullivan BM, Ho IC, Locksley RM: Divergent expression patterns of IL- 4 and IL-13 define unique functions in allergic immunity. Nat Immunol 2012;13:58-66 
29 Jacobsen EA, Ochkur SI, Pero RS, Taranova AG, Protheroe CA, Colbert DC, Lee NA, Lee JJ: Allergic pulmonary inflammation in mice is dependent on eosinophil-induced recruitment of effector T cells. J Exp Med 2008;205: 699-710.

-30 Rudmann DG, Moore MW, Tepper JS, Aldrich MC, Pfeiffer JW, Hogenesch H, Tumas DB: Modulation of allergic inflammation in mice deficient in TNF receptors. Am J Physiol Lung Cell Mol Physiol 2000;279:L1047L1057.

31 Choi IW, Sun K, Kim YS, Ko HM, Im SY, Kim JH, You HJ, Lee YC, Lee JH, Park YM, Lee HK: TNF- $\alpha$ induces the late-phase airway hyperresponsiveness and airway inflammation through cytosolic phospholipase $\mathrm{A}_{2}$ activation. J Allergy Clin Immunol 2005;116:537543.
-32 Guedes AG, Jude JA, Paulin J, Kita H, Lund FE, Kannan MS: Role of CD38 in TNF- $\alpha$-induced airway hyperresponsiveness. Am J Physiol Lung Cell Mol Physiol 2008;294:L290-L299.

33 Hessel EM, Van Oosterhout AJ, Van Ark I, Van Esch B, Hofman G, Van Loveren H, Savelkoul HF, Nijkamp FP: Development of airway hyperresponsiveness is dependent on interferon- $\gamma$ and independent of eosinophil infiltration. Am J Respir Cell Mol Biol 1997; 16:325-334.

34 Busse WW: The relationship of airway hyperresponsiveness and airway inflammation: airway hyperresponsiveness in asthma - its measurement and clinical significance. Chest 2010;138:4S-10S.

35 Galli SJ, Tsai M, Piliponsky AM: The development of allergic inflammation. Nature 2008; 454:445-454.

- 36 Laporte JC, Moore PE, Baraldo S, Jouvin MH, Church TL, Schwartzman IN, Panettieri RA Jr, Kinet JP, Shore SA: Direct effects of interleukin-13 on signaling pathways for physiological responses in cultured human airway smooth muscle cells. Am J Respir Crit Care Med 2001;164:141-148.
7 Adcock IM, Caramori G, Chung KF: New targets for drug development in asthma. Lancet 2008;372:1073-1087.

- 38 Corrigan CJ, Loke TK: Clinical and molecular aspects of glucocorticoid resistant asthma. Ther Clin Risk Manag 2007;3:771-787.

39 Sousa AR, Lane SJ, Soh C, Lee TH: In vivo resistance to corticosteroids in bronchial asthma is associated with enhanced phosyphorylation of JUN N-terminal kinase and failure of prednisolone to inhibit JUN N-terminal kinase phosphorylation. J Allergy Clin Immunol 1999;104:565-574.

40 Schonthaler HB, Guinea-Viniegra J, Wagner EF: Targeting inflammation by modulating the Jun/AP-1 pathway. Ann Rheum Dis 2011; 70(suppl 1):i109-i112. 